\title{
Pensar el Códice de Florencia de las Cantigas de Santa María. Algunas valoraciones sobre su construcción y deconstrucción
}

\author{
Analyzing the Códice de Florencia of the Cantigas de Santa María. Some \\ assessments on its construction and deconstruction
}

Laura Fernández Fernández

lfernand@ucm.es

Universidad Complutense de Madrid, España

Recepción: 23 Abril 2021

Aprobación: 02 Agosto 2021

Publicación: 01 Noviembre 2021

Cita sugerida: Fernández Fernández, L. (2021). Pensar el Códice de Florencia de las Cantigas de Santa María. Algunas valoraciones sobre su construcción y deconstrucción. Olivar, 21(34), e111. https://doi.org/10.24215/18524478e111
Resumen: El Códice de Florencia (BNCF BR 20) es el resultado de la manipulación, sustracción y reordenación de los folios de uno de los manuscritos de las Cantigas de Santa María de Alfonso X. Dicho manuscrito fue planteado en una cronología avanzada para recoger dos nuevos centenares de cantigas siguiendo las mismas pautas de composición y diseño que el llamado Códice Rico (RBME Ms. T-I-1). El fallecimiento del monarca en 1284 interrumpió su realización y parte de sus materiales quedaron sin concluir. Años más tarde sus folios fueron reordenados y algunas de sus iluminaciones completadas, dando lugar al manuscrito que hoy conocemos con ese sobrenombre. El análisis de su estructura nos permite profundizar en el estudio del cancionero alfonsí así como clarificar algunas de las singularidades de este códice.

Palabras clave: Alfonso X, Cantigas de Santa Maria, Manuscritos hispanos, Codicología.

Abstract: The Códice de Florencia (BNCF BR 20) is the result of the manipulation, subtraction and rearrangement of the folios of one of the manuscripts of the Cantigas de Santa Maria. This manuscript, produced at an advanced chronology, was created to collect two hundred new cantigas following the same composition and design guidelines as the so-called Códice Rico (RBME Ms. T-I-1). The death of the monarch in 1284 interrupted its completion and part of its materials remained unfinished. Years later, its folios were rearranged and some of its illuminations were completed, giving rise to the manuscript we know today by that name. The analysis of its structure allows us to study the Alfonsine collection of songs in greater depth, as well as to clarify some of the singularities of this codex.

Keywords: Alfonso X, Cantigas de Santa Maria, Manuscripts, Codicology. 
A principios de febrero de 2020 regresé a Florencia con la intención de revisar mi estudio codicológico del Ms. Banco Rari 20 de la Biblioteca Nazionale Centrale di Firenze [BNCF]; quería comprobar una vez más la estructura de los cuadernos, observar minuciosamente cada detalle de sus folios por si pudiera apreciar algún elemento material que previamente me hubiera pasado desapercibido y refrescar la emoción del diálogo directo con la obra para abordar algunas cuestiones que continúan abiertas en los estudios de este manuscrito. ${ }^{1}$ Habían pasado casi veinte años desde la primera vez que pude ver el Códice de Florencia de las Cantigas de Santa María en 2001, y no había vuelto a trabajar con él desde el año 2004, momento en el que pude llevar a cabo un estudio pormenorizado de la obra y de su fortuna. ${ }^{2}$ Los derroteros de mi investigación a partir de ese año me llevaron a introducirme de lleno en la problemática de los manuscritos científicos vinculados a la producción alfonsí, quedando las Cantigas en un discreto segundo plano, si bien persistente, emergiendo puntualmente para reclamar atención. En esos primeros meses del 2020, un año que se tornó triste y convulso, el Códice de Florencia reclamaba entonces pleno protagonismo en mi cabeza e intereses, y consideré oportuno aprovechar la ocasión para revisar la información que disponía hasta el momento, actualizarla y tratar de recomponer el puzle de sus folios una vez más. Realizada esta labor no sin titubeos y algunas dudas motivadas por las sucesivas manipulaciones a las que el códice se ha visto sometido en varias ocasiones, me gustaría actualizar la información de la obra, unificar algunas cuestiones dispersas y hacer algunas consideraciones adicionales sobre la realización del manuscrito.

\section{Cantigas de Santa María, Códice de Florencia ${ }^{3}$}

Como ha sido puesto de manifiesto en numerosos estudios, lo que definimos como Códice de Florencia es el estado fragmentario del manuscrito que fue planteado para recoger dos nuevos centenares de cantigas del cancionero mariano alfonsí, el gran proyecto poético del rey Alfonso X. La huella de esta empresa se puede detectar ya en 1269 cuando Cerverí de Girona reconoce al monarca como trovador de la Virgen, si bien asumió gran parte de los esfuerzos y recursos del ambiente intelectual de la corte y del escritorio regio a lo largo de la década de los setenta y especialmente en los últimos años del reinado. En lo que respecta a su definición material, el Códice de Florencia perpetúa la estructura del Códice Rico, con el que constituye un conjunto coherente que Gonzalo Menéndez Pidal (1962, p. 30) dio a conocer como "Códice de las historias", dividido en dos volúmenes, T y F, consideración que se ha mantenido con cierta fortuna en la historiografía cantigueira. No obstante, como señaló con acierto Martha Schaffer (1990-1991, p. 58), en el marco del proyecto global del cancionero, T fue concebido como una colección coherente y completa, reflexión que podemos reforzar con el análisis de los manuscritos (Schaffer, 2000; Fernández Fernández, 2011; 2012-2013, p. 98); por lo tanto podemos considerar que el Códice Rico fue diseñado en un primer momento como unidad independiente, por lo que no hubo un proyecto inicial de "Códice de las historias" que contemplara la totalidad de las cantigas editadas con este formato para ser realizado en dos volúmenes. ${ }^{4}$ Ese segundo volumen, en parte conservado en el actual Códice de Florencia, surgió como resultado de la evolución del cancionero alfonsí, y se proyectó como la continuación del Códice Rico muy probablemente cuando la selección de los poemas para este manuscrito ya se había realizado y su ejecución debía estar muy avanzada (Schaffer, 2000, pp. 189-190), por lo que ambos manuscritos, T y F, comparten características materiales, gráficas e icónicas, y responden a un mismo esquema editorial.

Pero también es importante señalar que ese manuscrito concebido como segundo volumen incorporó una serie de novedades y elementos diferenciadores que recogieron la experiencia previa convirtiéndose en una pieza de especial relevancia para la comprensión de la obra y su evolución.

En paralelo a la elaboración de F también se realizó E, el llamado Códice de los músicos; este manuscrito fue concebido como archivo del proyecto, para contener la totalidad de las composiciones realizadas, ${ }^{5} \mathrm{y}$ aunque comparte contenidos y artífices con $\mathrm{T}$ y F, su planteamiento editorial y funcional es muy diferente (Fernández Fernández, 2011 y 2012-2013). Este trabajo en paralelo generó complicaciones adicionales ya que los ejemplares de los poemas utilizados como modelo fueron consultados y utilizados por dos grupos 
de trabajo diferenciados, y las características de cada manuscrito, F y E, exigían unos tiempos de ejecución distintos, lo que ayuda a explicar las discordancias apreciables entre ambos códices (Schaffer, 2000, p. 189; Fidalgo, 2019, pp. 386-387).

Los poemas de $\mathrm{F}$ fueron diseñados en su versión definitiva de manera más sintética (Parkinson, 2000a y 2000b, pp. 267-273) para adecuarse a la mise en page desarrollada en T, lo que favoreció la distribución ideal de los elementos que constituyen la obra, texto, música e imagen, quedando el folio iluminado en un alto porcentaje de cantigas en el lado recto de los folios, objetivo que se había podido cumplir en las últimas cantigas de $T$, y que en $F$ se percibe de manera sistemática, aunque también encontramos ejemplos en los que dicha combinación no se cumple (Fernández Fernández, 2012-2013, p. 99). Este logro también fue producto de la combinación de texto y música a partir de diferentes modelos compositivos, utilizando una, dos o tres columnas en función de la extensión de los poemas, entre los que destaca un ingenioso esquema tímidamente ensayado en T (cantigas 132 (f. 186r), 135 (f. 189v), 164 (f. 219v)) que planteaba la copia del texto y su música en una única columna que ocupaba toda la caja de justificación, siendo el resto del poema copiado en dos o tres columnas, según su extensión, en la parte inferior del folio ${ }^{6}$ (Fig. 1) (Schaffer, 2000, p. 194).

Fig. 1. Cantigas de Santa María, Códice de Florencia, BNCF Ms. BR 20, f. 28v. (c) BNCF.

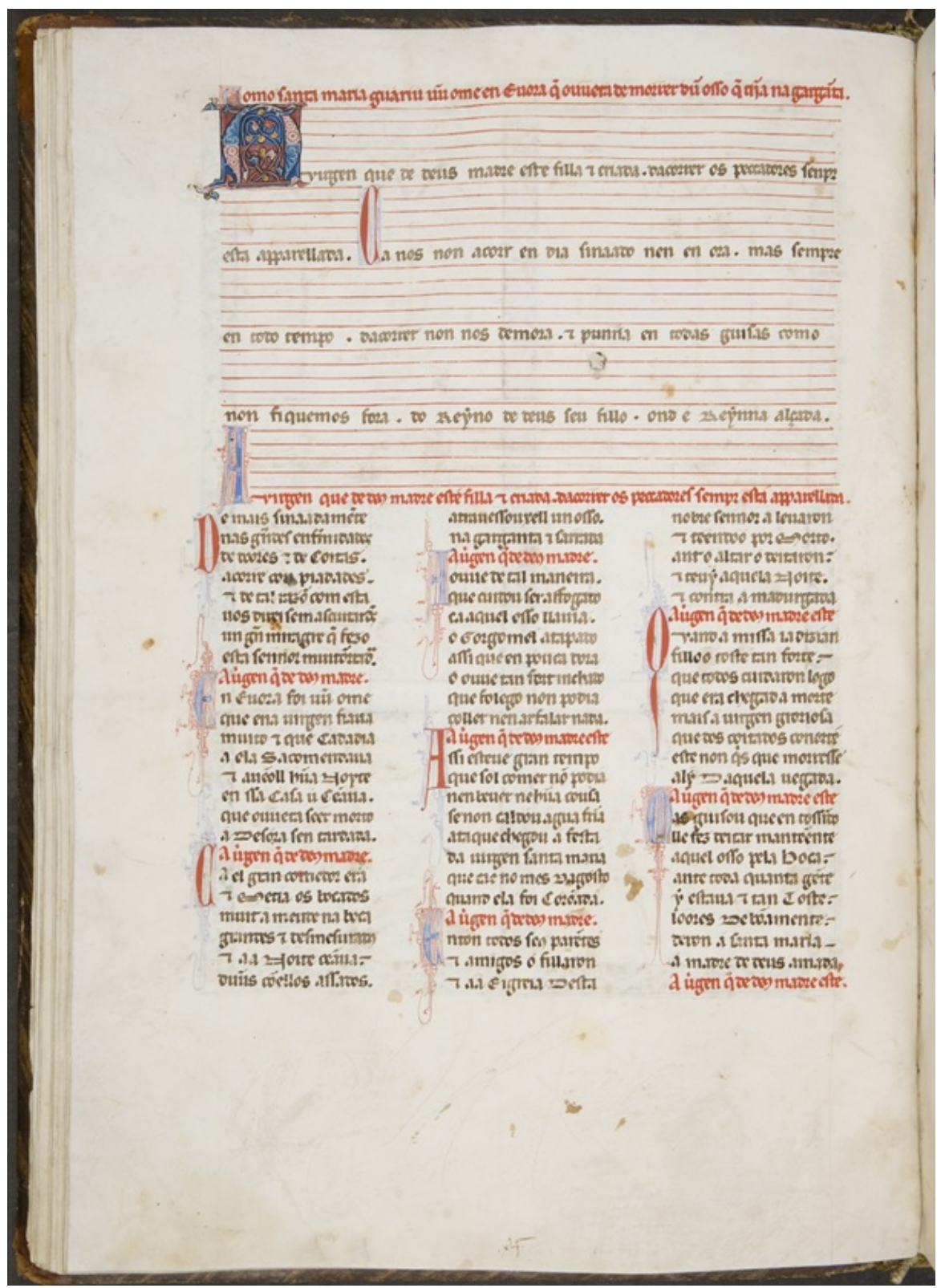


Igualmente se aprecia una depuración en el lenguaje pictórico que responde a esquemas plenamente establecidos y consolidados (Aita, 1922; Chico Picaza, 1991).

Su contenido, sin abandonar completamente la impronta de fuentes de tradición europea, asume una mirada centrada en el universo cercano al rey, quien aparece en más de una treintena de cantigas, y a su reino, reflejado en milagros de contenido local, en historias vinculadas a tradiciones peninsulares, y en acontecimientos históricos. ${ }^{7}$ En esta selección de poemas el monarca adquirió un rol diferenciado con respecto a $\mathrm{T}$, apareciendo como beneficiario de milagros e instructor e inspirador de fe mariana (Schaffer, 2000, p. 192; Greenia, 1993; Scarborough, 1986). Me pregunto si la presencia del monarca, de una manera mucho más acusada en las narrativas del segundo bloque de poemas y en su visualización, ${ }^{8}$ no pudo formar parte de la necesidad de reivindicación de su persona en un momento de máxima tensión en el reino como la vivida a partir de 1281 con las cortes de Sevilla, y posteriormente con el levantamiento de Sancho y el total desencuentro entre padre e hijo. No podemos olvidar que la lectura de las Cantigas de Santa María en clave política forma parte indisoluble de la evolución de la obra y de sus connotaciones simbólicas.

Un trabajo de esta magnitud y sofisticación exigía un largo recorrido y dedicación, tanto en la fase de conceptualización del proyecto, en su desarrollo a partir de la búsqueda, selección y definición de los materiales textuales, musicales e icónicos, y en su realización final. La localización de los poemas que pudieran servir como elemento de inspiración, su traducción en aquellos casos en los que las fuentes utilizadas estuvieran escritas en otras lenguas, su adaptación a las necesidades y estilo del cancionero alfonsí, y la creación de nuevos poemas procedentes de la tradición oral o que narrasen historias singulares, significó un esfuerzo monumental de planificación, organización y creatividad por parte de los talleres alfonsíes. De manera coetánea al trabajo textual se trabajaba en las composiciones musicales (Ferreira, 1994; Parkinson, 1987; Snow, 1980), y debemos asumir que, una vez tomada la decisión de realizar una edición historiada del cancionero, una decisión tardía tal y como veremos más adelante, también fue necesario trabajar en los procesos intermedios para la creación de la narración visual. Esta exigía igualmente la búsqueda de fuentes que sirvieran como motor e inspiración compositiva de determinados motivos, pero sobre todo de equipos capaces de enfrentarse al reto de construir un conjunto icónico de gran complejidad y sofisticación para el que en un alto porcentaje de casos no se disponía de modelos precedentes. ${ }^{9}$

Las fases de colección y composición marcaron la evolución del proyecto y la gradual generación de contenidos que se utilizarían para la compilación y materialización del cancionero en códices de aparato. ${ }^{10}$ La estructura de T, y posteriormente de F, dependió directamente de la selección de los poemas a partir de la combinación de cantigas narrativas y de loor, y de la incorporación de las cantigas quinales como pieza nuclear en la organización de los manuscritos al incluir dos folios iluminados a modo de díptico, manteniendo la secuencia vuelto-recto de manera inalterada a lo largo de todo el libro. ${ }^{11} \mathrm{Y}$ a pesar de que la labor de copia en el soporte definitivo se realizara con textos muy depurados, actualmente sabemos que la codificación final de los poemas y su distribución en el folio, incluso la incorporación de ciertos elementos textuales, no dependía única y exclusivamente del modelo que se estaba copiando, sino de principios de organización de la página asumidos por la persona encargada de esta labor (Parkinson, 2000b, p. 262).

Esta manera de trabajar pone de manifiesto que la realización de los códices historiados estuvo condicionada por el corpus de poemas seleccionados. Y si bien podemos pensar que la fase final de la ejecución de los manuscritos pudo avanzar en paralelo a la redacción de algunos textos, en el caso de $\mathrm{T}$ es lógico considerar que dicha selección estuviera prácticamente cerrada, si no cerrada por completo, cuando se inició el manuscrito; y por lo que respecta a F, a partir de la experiencia obtenida en la realización de $\mathrm{T}$, es probable que se pudiera avanzar en la confección del códice, al menos en la preparación de materiales y estructuración de contenidos, de manera coetánea a la finalización de los últimos doscientos poemas, que no debemos olvidar serían utilizados tanto en $\mathrm{F}$ como en $\mathrm{E}$. 
Dado que un número destacado de acontecimientos históricos reflejados en los poemas pueden ser datados en la década de los setenta, en el caso de los doscientos primeros poemas, y en el caso del bloque de doscientos a cuatrocientos algunos incorporan cronologías posteriores, 1280-1281, como ya he planteado en otras ocasiones, la cronología de estos manuscritos debe situarse necesariamente en los últimos años del reinado. Por otra parte, se ha insistido de manera razonada en la influencia que fray Juan Gil de Zamora pudo haber ejercido en el desarrollo del cancionero y no debemos olvidar que su retorno a Castilla desde París, ciudad a la que había marchado en 1272-1273 para llevar a cabo sus estudios, no se produjo hasta 1277-1278, lo que nos sitúa de nuevo en los últimos años de la década de los setenta en lo que respecta a la base textual de las Cantigas. A su regreso, Gil de Zamora probablemente trajo consigo libros, o conocimiento de ellos, como señala Elvira Fidalgo (2012-2013, p. 41), tal vez algún marial ilustrado que pudiera despertar en el monarca la idea de la continuación del cancionero con unas nuevas coordenadas. A este razonamiento podemos añadir otras cuestiones vinculadas con el hecho de la necesidad de una férrea organización de los equipos de trabajo involucrados en la realización de estos manuscritos, que no pudo dilatarse durante dos décadas como algunos autores han pretendido; ${ }^{12}$ por otra parte es fundamental reflexionar sobre la logística productiva del escritorio regio, sobre la necesidad de tener acceso a los materiales (pergamino, pigmentos), a profesionales para la copia del texto y la música, y a equipos de iluminadores. En este sentido la ciudad de Sevilla podía proporcionar las garantías necesarias para el correcto desarrollo de esta empresa coincidiendo con los últimos años del reinado y con la presencia del monarca en la ciudad, si bien la cuestión relacionada con la financiación necesaria para asumir esos gastos es un tema que exigiría un estudio en profundidad. Por otro lado, tal y como ya he expresado en otras ocasiones, considero que la dimensión material y simbólica que alcanzó el cancionero regio está estrechamente relacionada con el devenir de los acontecimientos en los últimos años de reinado.

La consulta y uso de estos manuscritos debió producirse fundamentalmente después de la muerte del rey, tal y como delatan algunas intervenciones tanto en $\mathrm{T}$ y $\mathrm{F}$, como en $\mathrm{E}$; curiosamente, el que muestra síntomas más acusados de uso es precisamente el Códice de Florencia debido a su agitada fortuna. A pesar de que durante años el universo cantigueiro ha construido la imagen de Alfonso X consultando y exhibiendo los códices historiados en la corte, todo parece indicar que la eclosión del cancionero alfonsí y su espléndida materialización coincidió en buena medida con los años finales del reinado, por lo tanto con una corte mermada y en tensión. De estos tres manuscritos, tan solo el Códice Rico pudo haber sido incorporado a un cierto uso de carácter performativo en ese contexto cortesano, puede que el Códice de los músicos en los últimos momentos de la vida del monarca. No obstante no debemos olvidar que previamente a los códices historiados al menos existió otro manuscrito que en 1276 estaba ya finalizado, tal y como relata la cantiga 95 de F (E209), códice que se podría identificar con el libro que sirvió como modelo a To (o para algunos autores con To); por otra parte existen referencias documentales de la difusión de algunas cantigas en Portugal (Ferreira, 2016), y lo cierto es que desconocemos si previamente a los códices historiados y al Códice de los músicos, existieron otros manuscritos de los que hemos perdido su huella, por lo que independientemente de la factura tardía de dichos libros, las Cantigas de Santa María como producto poético y musical debieron estar presentes en mayor o menor medida en el ambiente de la corte, y probablemente en algunos de los santuarios referenciados en el cancionero. No obstante, tal y como ha sido señalado por Kirstin Kennedy (2004, p. 211), el hecho de que el monarca no dotara de recursos a los lugares en los que tendrían que haberse interpretado las Cantigas no favoreció su incorporación a contextos ceremoniales, más allá de una posible interpretación de las cantigas dedicadas a las fiestas de María en el contexto de la Capilla Real en Sevilla (Ferreira, 2016, pp. 315-16). Por este motivo, tras la muerte del monarca, y a medida que el uso del gallegoportugués se hizo menos presente en la corte, la tradición poética de las Cantigas se fue extinguiendo hasta desaparecer del imaginario colectivo, permaneciendo únicamente como producto erudito al que pudieran acceder determinados personajes (Fernández-Fernández, 2021).

Vista la complejidad del proyecto y de su consecución material, no sorprende que a la muerte del rey en 1284 este segundo volumen historiado no se hubiera terminado. Aunque como ya hemos visto F y E se 
plantearon en paralelo hacia 1281, el equipo que trabajaba en $\mathrm{E}$ avanzó más rápido y se dio prioridad a su conclusión, tal vez porque su función se proyectaba más allá del contexto palaciego para ser utilizado con un carácter "paralitúrgico" en el marco de la capilla palatina y cumplir así lo establecido en el testamento del rey (Fernández Fernández, 2012-2013; Ferreira, 2016, p. 338).

No es extraño que un proyecto tan personal como este se viera bruscamente interrumpido, y que no hubiera un firme interés por parte del heredero en su finalización, al igual que ocurrió con otras obras de naturaleza científica estrechamente conectadas con don Alfonso. Sin embargo, Sancho IV no tuvo reparo en continuar el proyecto historiográfico y utilizar el relato histórico iniciado por su padre como herramienta de afirmación y legitimidad.

En el caso de F no se pudo finalizar la labor de copia de algunos de sus poemas, así como de buena parte de su iluminación. Tampoco se copió su notación musical, quedando un número considerable de sus folios preparados para recibir el contenido, bien con el pautado establecido para continuar la copia de las cantigas y de la música, o con las orlas, en diferentes estados de definición cromática, dispuestas para acoger la narrativa visual de sus historias.

Además del material que no llegó a ser realizado, el manuscrito, tal y como se puede extraer de su estudio directo y de las fuentes documentales que lo mencionan (Antonio,1998, II, p. 80), ${ }^{13}$ sufrió pérdidas de folios en diferentes momentos de su historia, lo que nos ha privado de parte de su contenido, textual e icónico.

A continuación, me centraré en algunos datos materiales obtenidos del trabajo directo con el manuscrito, fundamentalmente sobre la colación y la numeración.

\section{EL MANUSCRITO}

El BNCF Ms. BR 20 (F) es un códice de 131 folios de pergamino de buena factura (456x320 mm), con una guarda volante en papel al inicio y otra al final. El primer folio se encuentra mutilado en el margen inferior, habiendo perdido una cuarta parte del pergamino (Fig. 2).

La laguna está reintegrada con una pieza de pergamino de tonalidad más clara, perfectamente visible, y en el vuelto del folio, en la parte inferior derecha, se aprecian restos de trazos de pluma que delatan el motivo de la agresión, la cancelación de alguna señal que revelara marca de propiedad previa. En el margen derecho aparece el sello del fondo mediceo de la Biblioteca Palatina Mediceo Lotaringia de Francesco II y el de la BNCF (Fernández Fernández, 2005, p. 23).

Fig. 2: Cantigas de Santa Maria, Códice de Florencia, BNCF Ms. BR 20, f. 1r. (C) BNCF.

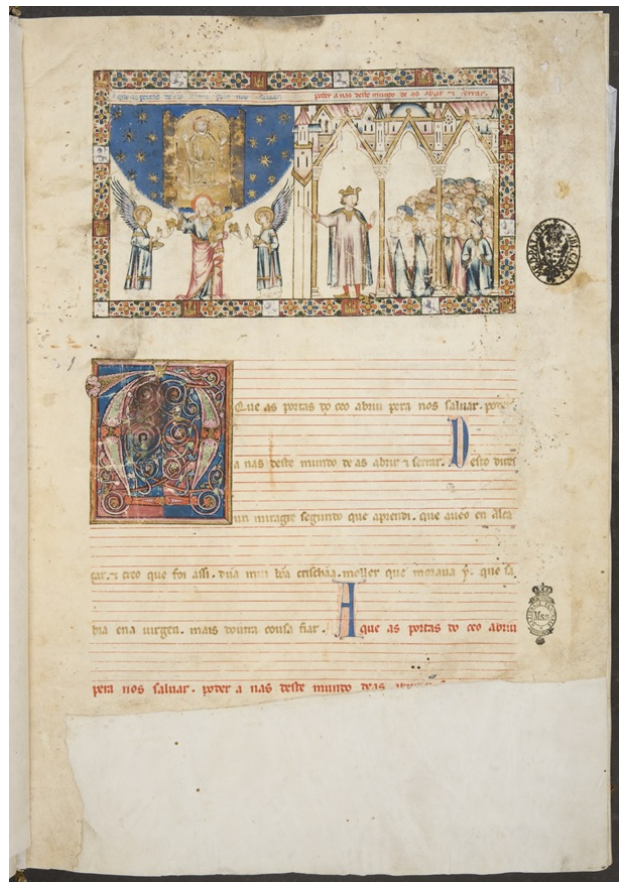


Su encuadernación responde a los modelos utilizados en la Biblioteca Palatina de Florencia durante el siglo XVIII (Fig. 3), momento en el que se incorporó a sus fondos: tabla forrada de piel marrón jaspeada con la técnica del estarcido, con estructura decorativa de encuadramientos, uno exterior y otro interior unidos por las esquinas, con decoración de hierros dorados con motivos floreados que incluyen remates de flor de lis, símbolo de la ciudad, tanto en los frentes, como en el lomo, cuya superficie se estructura en siete espacios con seis nervios. ${ }^{14}$ Se puede apreciar como los nervios de la encuadernación atraviesan parte de los cuadernos.

Fig. 3: Cantigas de Santa María, Códice de Florencia, BNCF Ms. BR 20, encuadernación. (C BNCF.

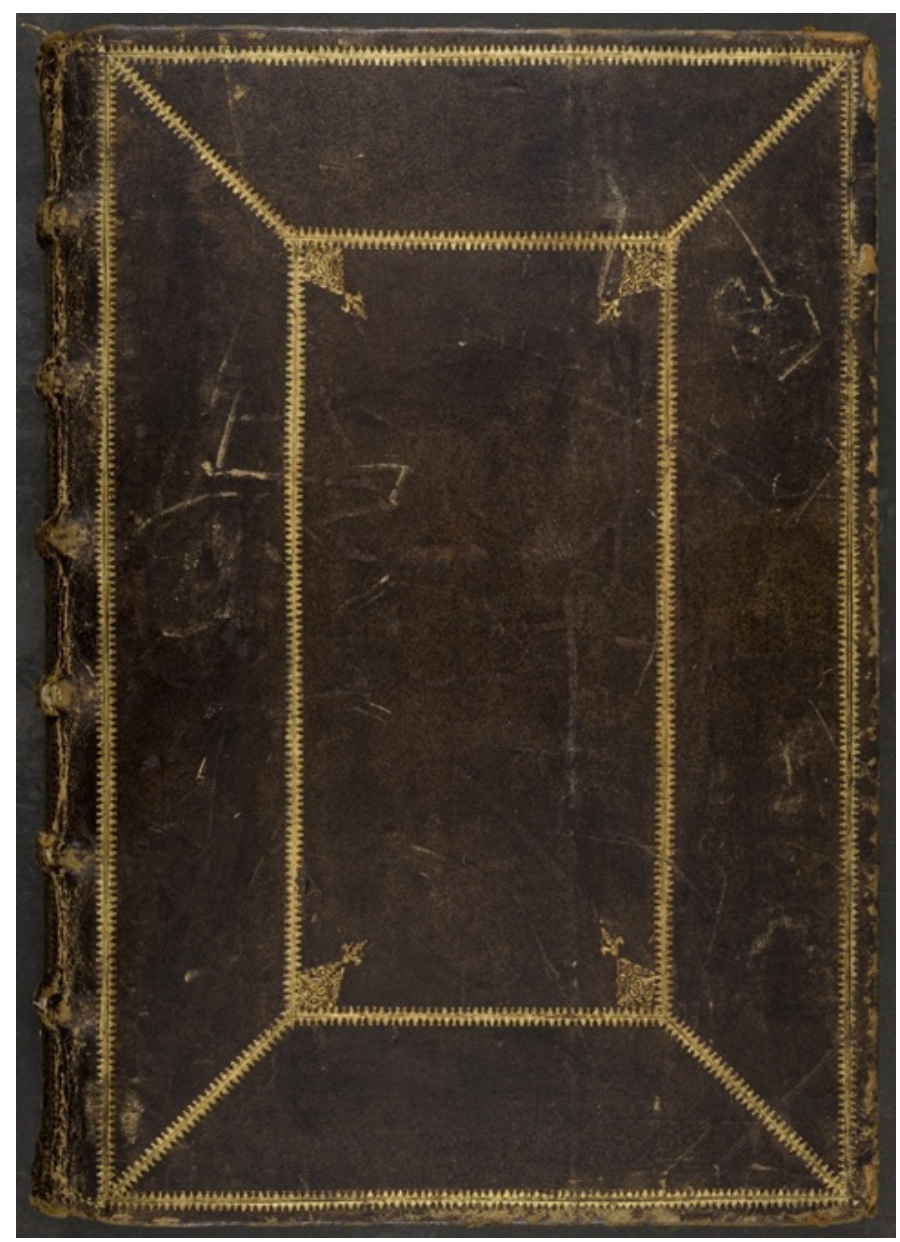

En la contratapa y la guarda podemos recorrer la historia florentina del manuscrito a partir de las diferentes signaturas anotadas a mano (5.2.7, II.I.213, Magl. XXXV.259bis, B.A. s. p.2.nº.7, B.R. 20).

El manuscrito cuenta con una numeración moderna en numerales arábigos en el margen superior derecho, otra numeración moderna en lápiz junto al inicio de las cantigas, pero también incorpora una numeración antigua en el margen inferior central del vuelto de sus folios que muestra que en un momento indeterminado el manuscrito contó al menos con ciento sesenta y seis folios; no obstante, en origen debió tener un número mayor, tal y como trataré de explicar a continuación. Es probable que algunos de ellos quedaran sin finalizar, tan sólo con la orla para las imágenes o el pautado para el texto y la música, tal y como atestiguan algunos de los folios que nos han llegado en esas condiciones, si bien el hecho de que algunos folios fueran sustraídos delata que estuvieron mayoritariamente ejecutados. Los cortes presentan restos de pigmento rojo. 
A la guarda está adherido el primer folio en pergamino, en el que en la parte superior podemos observar una viñeta rectangular en la que el monarca se dirige a un grupo de cortesanos, todos ubicados bajo una estructura arquitectónica que parece recrear la residencia palatina en mitad del tejido urbano, mientras señala la escena de la Virgen y el niño abriendo las "portas do ceo" que parece imitar la apertura de un retablo tabernáculo. Esta composición replica la impaginación del f. $5 \mathrm{r}$ del Códice Rico, en el que la conocida imagen de apertura nos muestra al monarca rodeado de algunos de sus colaboradores, copistas, cantores e instrumentistas, marcando el inicio de la obra. Aunque dicha cantiga aparece en E, y en la relación de Meettmann, como la número 246, tal y como ha señalado Elvira Fidalgo (2019, p. 383) su composición y temática se entiende en el lugar que ocupa como primera cantiga de F, por lo tanto, debe ser entendida como la cantiga 201 en el compendio de los códices de las historias.

El manuscrito termina en el folio 131r (Fig. 4), con la copia de la cantiga numerada como 104 (E325) interrumpida y en el folio 131v el espacio para el folio iluminado. Resulta verdaderamente curioso que la copia de las estrofas de la cantiga no se ha realizado de manera correlativa, sino una vez distribuido el texto en tres columnas, se ha copiado la primera estrofa de cada columna, y a continuación la segunda, que ha quedado interrumpida en la tercera columna. Este atípico sistema de copia es la causa de que en lugar de contar con un número de estrofas correlativas, contemos con estrofas alternas de la cantiga. Por otra parte es una evidencia más de la existencia de borradores previos estructurados y de un complejo sistema de copia (Parkinson 2021).

Fig. 4: Cantigas de Santa Maria, Códice de Florencia, BNCF Ms. BR 20, f. 131r. (C BNCF.

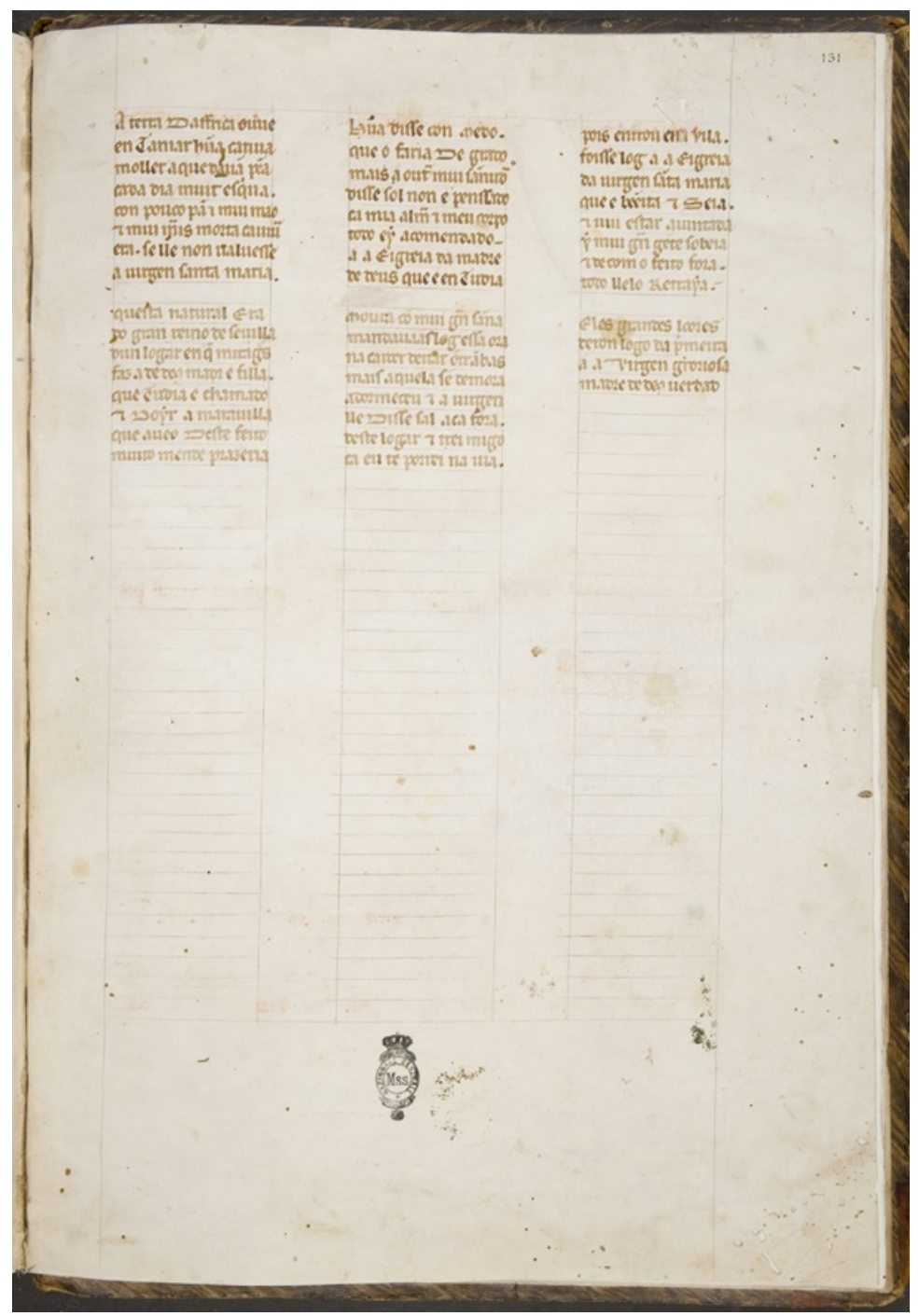




\section{LA COLACIÓN ACTUAL}

La estructura actual del libro es el resultado de un proceso de reorganización de su contenido después de que un número indeterminado de sus folios hubiera desaparecido. A partir de la localización de las lagunas que nos marca la numeración podemos estimar una pérdida de al menos sesenta y tres folios, lo que supone un porcentaje significativo del total; no obstante, como ya he mencionado, las lagunas de contenido y las fuentes documentales que disponemos indican que el número de folios perdidos pudo ser mayor. De las doscientas cantigas que pudo contener según la descripción de Nicolás Antonio, quedan trazas de ciento trece (noventay dos con el espacio para texto e imagen; el texto parcial de once y los folios correspondientes a las iluminaciones de diez).

A pesar de las pérdidas, nueve cuadernos han llegado intactos ${ }^{15}$ (ff. 22-29, 34-41, 42-49, 50-57, 62-69, 70-77, 94-101, 102-109, 124-131), todos cuaterniones, siguiendo el modus operandi del escritorio regio. Contar con nueve cuadernos completos nos permite confirmar lo que autores precedentes ya han planteado, que $\mathrm{F}$ mantiene la estructura de cantigas narrativas y loores de $\mathrm{T}$ incluyendo la fórmula de doble folio iluminado para las cantigas quinales, de las que han llegado completas las siguientes: ff. 24v-25r, 43v-44r, $57 \mathrm{v}-58 \mathrm{r}, 67 \mathrm{v}-68 \mathrm{r}, 103 \mathrm{v}-104 \mathrm{r}, 128 \mathrm{v}-129 \mathrm{r}$. Es interesante señalar que la pérdida de material coincide con la desaparición de algunos folios iluminados de cantigas quinales: la primera parte de la quinal cuyo final encontramos en el f. 6r; el final de la que se inicia en el f. 33v; el final de la que inicia en el f. 86v; el inicio de la que finaliza en el f. 92r; dicha pérdida de material y la sucesiva reordenación también generó la creación de falsas quinales, como las formadas por los ff. 31v-32r, 59v-60r y 86v-87r, que vinculan los folios iluminados de dos cantigas diferentes.

Lamentablemente los folios han sido refilados, es probable que en varias ocasiones, lo que ha eliminado la posible información de signaturas ${ }^{16}$ más allá de la numeración referida, y han hecho disminuir sensiblemente su tamaño, sobre todo su altura. Es probable que la numeración de las cantigas que discurre en el margen superior de $\mathrm{T}$ a modo de título corriente no se llegara a incluir en $\mathrm{F}$ ya que en la lógica de las fases de ejecución del manuscrito dicha numeración se habría llevado a cabo en la fase de finalización del libro, con los cuadernos ya ordenados (Parkinson, 2000b, p. 261), algo que no se llegó a producir hasta mucho tiempo después.

Por otra parte, la propia estructura de cuadernos que nos ha llegado también presenta problemas, ya que en ocasiones parece que ha sido rehecha en función de los folios que consiguieron sobrevivir. No obstante gracias a la numeración antigua y a la secuencia texto-imagen que marcan las propias cantigas podemos hacer una reconstrucción bastante ajustada del manuscrito que paso a describir a continuación. ${ }^{17}$

El folio 1 aparece pegado a la guarda, aunque probablemente hiciera bifolio con el actual número 7; desde el folio 1 presenta una estructura correlativa texto-imagen hasta el folio $5 \mathrm{v}$, sin embargo, entre este y el siguiente necesariamente tuvo que existir otro folio en el que tendríamos la continuación del texto que se ve interrumpido, y en su vuelto tendría la imagen que haría pareja con la del folio 6r, ya que esta sería la primera cantiga quinal del manuscrito. Efectivamente las viñetas del folio 6r narran solamente la mitad final de la historia. Entre los folios 5 y 6 queda interrumpida la ley de Gregory, otro elemento que señala la laguna del mencionado folio que haría bifolio con el folio 3. El resto de las cantigas del cuaderno están completas en su desarrollo textual e icónico. El cosido del bramante parece agrupar de forma un tanto artificiosa los folios que han permanecido, si bien la estructura original del cuaderno no se ha perdido. El cuaderno siguiente se iniciaría en el actual folio 8, también un cuaternión al que le faltan los dos últimos folios (entre el 13 y el 14), 
que harían bifolio con el 8 y el 9 respectivamente; sin embargo, al haber eliminado estos folios, sus parejas, el 8 y 9 , han sido agrupados con una pieza de pergamino a modo de cartivana a la que se adhieren ambos. Este cuaderno también resulta problemático ya que aunque la secuencia texto-imagen aparentemente es correcta entre los folios $7 \mathrm{v}$ hasta el 13v, sin embargo, la primera cantiga de loor que se tendría que ubicar en el actual folio 10v es una cantiga narrativa, precisamente una de las que narra un episodio de la vida de Fernando III (E292). Este error, que no se vuelve a producir en el resto del manuscrito, al menos en las secuencias que podemos reconstruir a partir de los cuadernos actuales, es indicio de que este cuaderno está descolocado. Precisamente la iluminación del folio 8r, el actual inicio del segundo cuaderno, había quedado sin realizar, de hecho es una de las que se intenta completar posteriormente, la de la enfermedad de la reina Beatriz, por lo que tal vez se intercambiara ese cuaderno con otro cuyo folio iluminado inicial tampoco se había realizado y por lo tanto no contaban con un referente visual en el orden de los cuadernos. Si buscamos un cuaderno que pudiera dar respuesta a la secuencia de cantigas narrativas y de loor necesaria para ese espacio, justo el penúltimo cuaderno (ff. 118-123), al que le falta el bifolio exterior, podría encajar con dicha secuencia; además este cuaderno no se relaciona ni con el precedente ni con el siguiente en su ubicación actual, y la secuencia de cantigas coincide con la que aparece en E (208-211) ${ }_{18}^{18}$ por lo que tendría sentido su ubicación al principio del manuscrito como segundo cuaderno. Esto probablemente tuvo lugar con posterioridad al diseño de $\mathrm{F}$, en el momento en el que se reorganizaron sus folios y se numeraron. El tercer cuaderno está prácticamente completo, únicamente le falta el bifolio central entre los folios 16 y 17; del cuarto únicamente restan los folios 20 y 21 , que crearían el bifolio exterior del cuaderno al que le faltan los tres bifolios internos; el siguiente cuaderno está completo, 22-29; del siguiente hemos conservado cuatro folios, 30-33, y nos faltan otros cuatro entre el 31 y el 32; entre los folios 33 y 34 tenemos otra laguna identificada ya que en el $33 \mathrm{v}$ se rompe una cantiga quinal, por lo que es probable que hubiera al menos un cuaderno adicional; los tres cuadernos siguientes están completos, 34-41, $42-49$ y 50-57; del siguiente conservamos cuatro folios 58-61, y de nuevo faltarían otros cuatro entre el 59 y $60,{ }^{19}$ en este caso sustraídos antes de que se llevara a cabo la numeración romana; los cuadernos del 62-69 y 70-77 están completos; entre el 78 y 82 aparentemente nos faltan tres folios, dos entre el 79 y 80 , y se aprecian restos de un folio arrancado entre el 80 y $81 ; ;^{20}$ en el folio $82 \mathrm{v}$ tenemos el texto de una cantiga de loor a la que le falta el folio con la iluminación, ya que no se corresponde con el siguiente, por lo que tendríamos de nuevo una laguna identificada, probablemente otro cuaderno, aunque la numeración romana es correlativa, por lo que de nuevo estos folios desaparecieron antes de que se numerasen; entre los folios 83 y 84 faltan seis; entre el 85 y el 89 faltan otros tres, uno entre el 86 y el 87 y dos entre el 88 y el 89; del siguiente cuaderno, 90-93, faltan cuatro folios entre el 91 y el 92; ${ }^{21}$ los dos siguientes están completos, 94-101 y 102-109; del siguiente se conservan cuatro folios, 110-113, y probablemente faltan tres folios entre el 109 y el 110, y uno después del $113,{ }^{22}$ pero el bifolio externo de este cuaderno se habría perdido antes de la numeración; ${ }^{23}$ del siguiente, 114-117, nos faltarían los dos bifolios centrales del cuaderno, por lo tanto cuatro folios entre el 115 y 116 , que también desaparecieron antes de la numeración romana; el siguiente cuaderno ha perdido el bifolio externo, y como ya he mencionado este realmente sería el segundo cuaderno del manuscrito; el último cuaderno está completo, ff. 124-131 (Fig. 5). 
Fig. 5: Cantigas de Santa María, Códice de Florencia, BNCF BR 20, esquema de cuadernos. (C BNCF.

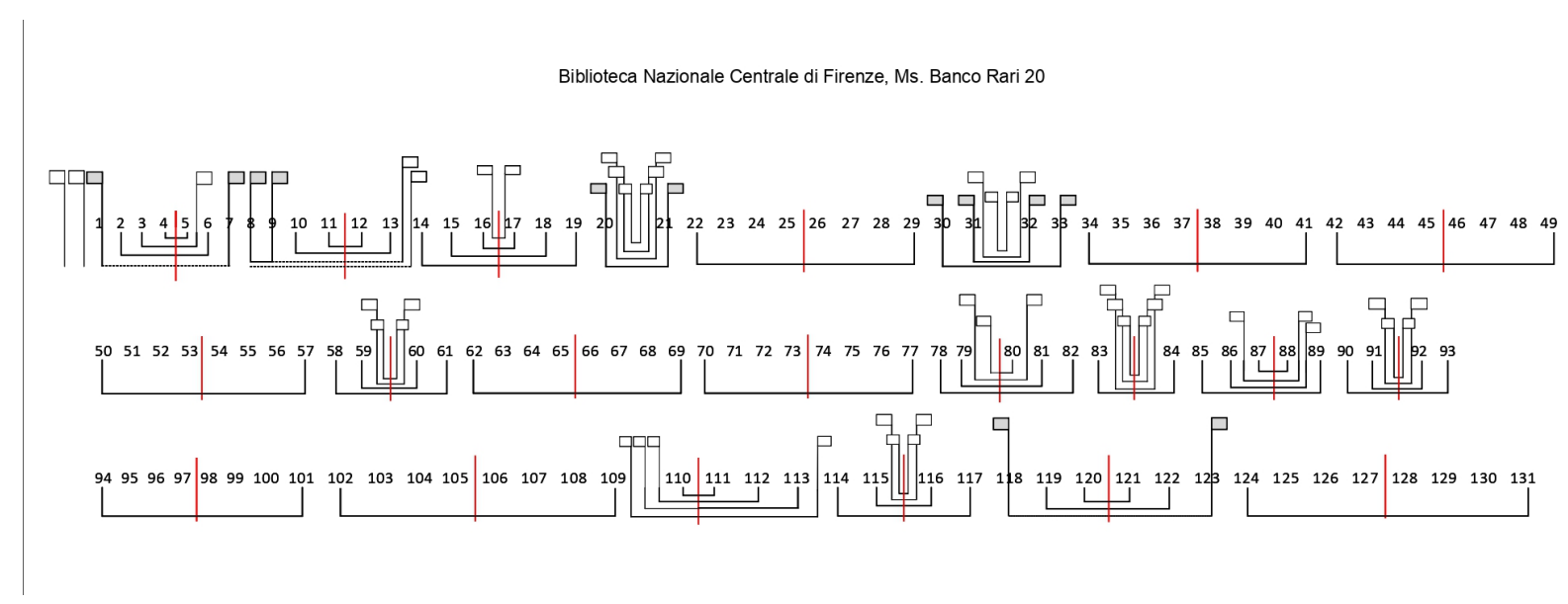

Gracias a la relación texto-imagen podemos corroborar en buena medida el orden de los cuadernos. Debido a las lagunas que he mencionado, de las que desconocemos las cantigas que contenían, no podemos afirmar la secuencia completa, pero salvo por las alteraciones del intercambio entre el segundo y el vigésimo primer cuaderno, el resto de los cuadernos son correlativos, ${ }^{24}$ por lo tanto, el manuscrito tiene su propia organización y sus folios no se encuentran desordenados.

\section{LA NUMERACIÓN}

Después de la muerte del rey, el trabajo en F se interrumpió, y debió quedar sin encuadernar durante un largo periodo, lo que pudo ser causa del extravío de algunos folios. Este material inconcluso se reactivó en un momento determinado y sus folios fueron numerados con numerales romanos en el vuelto, en el margen inferior, casi al borde del mismo, lo que ha causado su pérdida en algunos casos al ser refilados en varias ocasiones. ${ }^{25}$ Es probable que en ese momento el manuscrito fuera encuadernado. Como ya he mencionado, esta numeración recoge ciento sesenta y seis folios, dos de ellos al principio, antes del actual folio 1, lo que nos plantea la existencia de alguna pieza introductoria que pudiera anteceder a la primera cantiga de este segundo volumen. Antes de llevar a cabo la numeración como ya hemos visto se alteró el orden de dos cuadernos.

Por lo que respecta a la paleografía de estas cifras, no es lo suficientemente clara para precisar en qué momento se realizó (Fernández Fernández, 2012-2013, p. 100), aunque de lo que no hay duda es que dicha numeración es totalmente ajena al proceso de elaboración original del manuscrito, algo que ya observó Nella Aita (1922). Esta afirmación queda plenamente justificada al observar que la numeración no ha tenido en cuenta algunas de las múltiples lagunas de texto e imágenes existentes en el manuscrito, relacionando en ocasiones el texto de una cantiga con la imagen de otra, poniendo correlativos fragmentos de texto de diferentes cantigas, o construyendo "falsas quinales". Por lo tanto, antes de llevar a cabo dicha numeración ya habían sido sustraídos algunos folios, y otros fueron eliminados después de su ejecución. En qué momento se numeraron los folios no queda claro, si bien la grafía puede situarse en el siglo XIV, ${ }^{26}$ lo que apunta como momento más oportuno el reinado de Alfonso XI, en relación directa con otras intervenciones realizadas sobre el manuscrito (Sánchez Ameijeiras, 2002; Fernández Fernández, 2012). 
Como ya conocemos bien, $\mathrm{F}$ experimentó varias intervenciones, se completaron los rostros y manos de algunas composiciones, e incluso se intentó ilustrar dos de las cantigas que aparentemente no habían sido diseñadas. ${ }^{27}$ Dicha intervención, de gran interés simbólico al buscar la ilustración de dos cantigas vinculadas con Fernando III y Beatriz de Suabia, sin embargo no estuvo a la altura de la pericia técnica visible en el resto del manuscrito. ${ }^{28} \mathrm{El}$ códice se mantuvo durante un largo periodo vinculado al corpus librario de la Corona, y en 1474 salió del entorno regio para iniciar un largo e interesante periplo que lo llevaría por diferentes manos, algunas de las cuales, como ya hemos visto, se permitieron sustraer parte de sus folios, mermando y alterando su contenido. A pesar de ello el Códice de Florencia nos sigue sorprendiendo por la delicadeza de sus iluminaciones, por la creatividad de sus recursos de organización de contenido, y muy especialmente por mantener activo nuestro interés sobre el cancionero alfonsí y el proyecto cultural del rey Sabio, cuya memoria celebramos en este año 2021.

\section{REFERENCIAS}

Aita, N. (1921). O códice florentino de cantigas de Affonso, o Sábio. Revista de Lingua Portuguesa, 13, 187-200; 14 , 105-128 y 18, 153-160.

Aita, N. (1922). O Codice Florentino das Cantigas do Rey Affonso, o Sabio. Rio de Janeiro: Litho-Typ. Fluminense. Alfonso X (1986-1989). Cantigas de Santa María, edición de W. Mettmann. Madrid: Castalia, 3 vols.

Antonio, N. (1998). Biblioteca Hispana Antigua, Tomo II. Madrid: Fundación Universitaria.

Chico Picaza, M.V.(1987). Composición pictórica en el Códice Rico de las Cantigas de Santa María. Madrid: Universidad Complutense.

Chico Picaza, M.V. (1991). La Ilustración del Códice de Florencia. En El Códice de Florencia de las Cantigas de Alfonso X el Sabio. Ms. B.R.20 de la Biblioteca Nazionale Centrale (pp. 125-143). Madrid: Edilán.

Chico Picaza, M.V. (2012 - 2013). Composición, estilo y texto en la miniatura del Códice Rico de las CSM. Alcanate, 8, 161-189.

Domínguez Rodríguez, A. (1976). Filiación estilística de la miniatura Alfonsina. En España entre el Mediterráneo y el Atlántico. Actas del XXIII Congreso Internacional de Historia del Arte (Granada, 1973), vol. I (pp. 345-358). Granada: Universidad de Granada.

Fernández Fernández, L. (2005). Historia Florentina de las Cantigas de Santa Maria, Mss. B.R. 20. Reales Sitios. Revista del Patrimonio Nacional, 164, 18-29.

Fernández Fernández, L. (2008-2009). Las Cantigas de Santa María: fortuna de sus manuscritos. Alcanate. Revista de Estudios Alfonsies, VII, 323-348.

Fernández Fernández, L. (2011). “Este livro, com’ achei, fez á onr' e á loor da virgen santa maria”. El proyecto de las Cantigas de Santa María en el marco del escritorio regio. Estado de la cuestión y nuevas reflexiones. En Las Cantigas de Santa María, el Códice Rico, Ms. T-I-1, RBME (pp. 43-78). Madrid: Testimonio Editorial Patrimonio Nacional.

Fernández Fernández, L. (2012-2013). Los manuscritos de las Cantigas de Santa María: definición material de un proyecto regio. Alcanate. Revista de Estudios Alfonsies IX, pp. 79-115.

Fernández Fernández, L. (2021). "Del scriptorium a la biblioteca: la fortuna de los manuscritos alfonsíes en la Real Biblioteca del Monasterio de El Escorial". En Los códices del rey Sabio (pp. 49-71). Madrid: Patrimonio Nacional. 
Fernández Fernández, L. y Ruiz García, E. (2011). Quasi liber et pictura. Estudio codicológico del Ms. T-I-1, RBME. En Las Cantigas de Santa María, el Códice Rico, Ms. T-I-1, RBME (pp. 107-143). Madrid: Testimonio Editorial - Patrimonio Nacional.

Fernández Pousa, R. (1956). Menéndez Pelayo y el códice florentino de las Cantigas de Santa María de Alfonso X. Revista de Archivos, Bibliotecas y Museos, 62(1), 235-255.

Ferreira, M. P. (1994). The Stemma of the Marian Cantigas: Philological and Musical Evidence. Cantigueiros, 6, 58-98.

Ferreira, M. P. (2004). Rondeau and Virelai: The Music of Andalus and the Cantigas de Santa Maria. Plain song and Medieval Music, 13, 127-40.

Ferreira, M.P. (2011). A música no Códice Rico: formas e notaçao en Las Cantigas de Santa María, el Códice Rico, Ms. T-I-1, RBME (pp. 107-143). Madrid: Testimonio Editorial - Patrimonio Nacional.

Ferreira, M. P. (2015). Rhythmic Paradigms in the Cantigas de Santa María: French versus Arabic Precedent. Plain song and Medieval Music, 24, 1-24.

Ferreira, M. P. (2016). The Medieval Fate of the Cantigas de Santa María. Journal of the American Musicological Society, 69(2), 295-353.

Fidalgo, E. (1990). La estructura narrativa de las cantigas marianas de Alfonso X: Aproximación a distintos tipos de análisis. Bulletin of the Cantigueiros de Santa Maria, 3, 5-15.

Fidalgo, E. (1993). Aproximación a un análisis del esquema estructural de las Cantigas de Santa María (con relación a sus fuentes). Actas do IV Congresso da Associação hispânica de Literatura Medieval (pp. 325-332). Lisboa: Cosmos.

Fidalgo, E. (2002). As cantigas de Santa María. Vigo: Xerais de Galicia Edicións.

Fidalgo, E. (2012-2013). La gestación de las Cantigas de Santa María en el contexto de la escuela poética gallegoportuguesa. Alcanate, 8, 17-42.

Fidalgo, E. (2019). Cuando las Cantigas de Santa María eran "a work in progress": el códice de Florencia. En I. Tomassetti (Coord.), Avatares y perspectivas del medievalismo ibérico, Vol. I (pp. 379-388). San Millán de la Cogolla: Cilengua.

Fidalgo, E. y Guiadanes, A. F. (2020). La escritura de los códices de las Cantigas de Santa. En E. Fidalgo (Ed.), Alfonso X el Sabio: cronista y protagonista de su tiempo (pp. 249-268). Logroño: Cilengua.

Filgueira Valverde, J. (1979). El texto. Introducción histórico-crítica, transcripción, versión castellana y comentarios, en El "Códice rico" de las Cantigas de Alfonso X el Sabio. Ms T.I.1 de la Biblioteca de El Escorial (pp. 33-264). Madrid: Edilán.

García Cuadrado, A. (1993). Las Cantigas: el códice de Florencia. Murcia: Universidad de Murcia.

García Solalinde, A. (1918). El Códice florentino de las Cantigas y su relación con los demás manuscritos. Revista de Filología española, $V$, 143-179.

Greenia, G. (1993). The Politics of Piety: Manuscript Illumination and Narration in the Cantigas de Santa María. Hispanic Review, 61, 325-344.

Hernández Serna, J. (1989). El Códice de Florencia B.R. 20 de "Las Cantigas de Santa María". (Reflexiones ante una posible e inmediata edición monumental). Murgetana, 78, 71-101.

Jackson, D. A (4-6 September 2002). Proposed Reconstruction of the Disordered Quires of Florence, Biblioteca Nazionale Centrale Banco Rari 20. Conferencia en The City and the Book, International Congress, Florence, accessible on-line.

Kennedy, K. (2004). Alfonso's Miraculous Book: Patronage, Politics, and Performance in the 'Cantigas de Santa María'. En N. H. Petersen y M. B. Bruun (Eds.), The Appearance of Medieval Rituals: The Play of Construction and Modification (pp. 199-212). Turnhout: Brepols.

Kennedy, K. (2019). Alfonso X of Castile-León. Royal Patronage, Self-Promotion and Manuscripts in Thirteenth-Century Spain. Amsterdam: Amsterdam University Press.

Menéndez Pidal, G. (1951). Cómo trabajaron las escuelas alfonsíes. Nueva Revista de Filología Hispánica, V, 363-380.

Menéndez Pidal, G. (1962). Los manuscritos de las Cantigas. Cómo se elaboró la miniatura alfonsí. Boletín de la Real Academia de la Historia, CL, 25-51. 
Montoya Martínez, J. (1986). El Códice de Florencia: una nueva hipótesis de trabajo. Romance quarterly, 33, 323-329. Montoya Martínez, J. (1987). Algunas precisiones acerca de las Cantigas. En I. J. Katz y J. E. Keller (Eds.), Studies on the "Cantigas de Santa Maria": Art, Music and Poetry: Proceedings of the International Symposium on the "Cantigas de Santa Maria" of Alfonso X, el Sabio (1221-1284) in Commemoration of its 700th Anniversary Year 1981 (New York, November 19-21) (pp. 367-386). Madison: Hispanic Seminary of Medieval Studies.

Montoya Martínez, J. (1999). Composición, estructura y contenido del cancionero marial de Alfonso X. Murcia: Real Academia "Alfonso X el Sabio".

O'Callaghan, J. (1998). Alfonso X and the 'Cantigas de Santa Maria': A Poetic Biography. Leiden/Boston/Cologne: Brill.

Parkinson, S. (1987). False refrains in the Cantigas de Santa Maria. Portuguese Studies, 3, 21-55.

Parkinson, S. (1988). The First Reorganization of the Cantigas de Santa María. Bulletin of the Cantigueiros de Santa María, I(2), 91-97.

Parkinson, S. (2000a). Phonology and metrics: aspects of rhyme in the CSM. En A. Deyermond, (Ed.), Proceedings of the 10th Colloquium of the Medieval Hispanic Research Seminar (pp. 131-144). London: Department of Hispanic Studies, Queen Mary and Westfield College.

Parkinson, S. (2000b). Layout in the Códices ricos of the Cantigas de Santa María. Hispanic Research Journal, 1(3), 243-274.

Parkinson, S. (2007). The Evolution of Cantiga 113: Composition, Recomposition, and Emendation in the Cantigas de Santa María. La Coronica, 35(2), 227-272.

Parkinson, S. (2011). Alfonso X, Miracle Collector. En Las Cantigas de Santa María, el Códice Rico, Ms. T-I-1, RBME (pp. 79-106). Madrid: Testimonio Editorial - Patrimonio Nacional.

Parkinson, S. (2021). Doing lines: refrains and copyists in the Cantigas de Santa Maria. Medievalia, 52/2, 131-153.

Parkinson, S. y Jackson, D. (2006). Collection, Composition, and Compilation in the Cantigas de Santa Maria. Portuguese Studies, 22, 159-172.

Prado-Vilar, F. (2002). In the Shadow of the Gothic Idol: The Cantigas de Santa Maria and the Imagery of Love and Conversion, tesis doctoral. Harvard University.

Prado-Vilar, F. (2005). The Gothic Anamorphic Gaze: Regarding the Worth of Others. En Robinson, C. y Rouhi, L. (Eds.), Under the influence: Questioning the comparative in Medieval Castille (pp. 67-100). Leiden: Brill.

Prado-Vilar, F. (2011). The Parchment of the Sky: Poiesis of a Gothic Universe en Las Cantigas de Santa Maria, el Códice Rico, Ms. T-I-1, RBME. Madrid: Testimonio Editorial - Patrimonio Nacional.

Procter, E. S (1951). Alfonso X of Castile: Patron of Literature and Learning. Oxford: Clarendon Press.

Sánchez Ameijeiras, R. (2002). La fortuna sevillana del códice florentino de las Cantigas: tumbas, textos e imágenes. Quintana, 1, 257-273.

Sánchez Ameijeiras, R. (2012-2013). Del salterio al marial: sobre las fuentes de las imágenes de los Códices de las Historias de las Cantigas de Santa María. Alcanate, 8, 55-80.

Santiago Luque, A., Chico Picaza, M.V y Domínguez Rodríguez, A. (1991). El códice de Florencia de las cantigas de Alfonso X el Sabio: ms. B.R.20 de la Biblioteca Nazionale Centrale. Madrid: Edilán, 2 vols.

Scarborough, C. L. (1986). Alfonso X: Monarch in Search of a Miracle. Romance Quarterly, 33, 349-354.

Scarborough, C. L. (2011). Unas observaciones sobre el códice de Florencia de las Cantigas de Santa María. En M. J. Alonso García, M. L. Dañobeitia Fernández y A. R. Rubio Flores (Eds.), Literatura y cristiandad: Homenaje al profesor Jesús Montoya Martínez (con motivo de su jubilación). Estudios sobre hagiografía, mariología, épica y retórica (pp. 395-402). Granada: Universidad de Granada.

Schaffer, M. E. (1990\#1991). Epigraphs as a Clue to the Conceptualization and Organization of the Cantigas de Santa María. La Coronica, 19(2), 57-88.

Schaffer, M. E. (1999). Los códices de las Cantigas de Santa María: su problemática. En J. Montoya Martínez y A. Domínguez Rodríguez (coords.), El Scriptorium Alfonsi: de los Libros de Astrologia a las Cantigas de Santa María (pp. 127-148). Madrid: Editorial Complutense. 
Schaffer, M. E. (2000). The "Evolution" of the Cantigas de Santa Maria: The Relationships between MSS T, F, and E. En S. Parkinson (Ed.), Cobras e son. Papers on the Text, Music and Manuscripts of the 'Cantigas de Santa Maria' (pp. 186-213). Oxford: Legenda.

Snow, J. (1980). Self-Conscious References and the Organic Narrative Pattern of the Cantigas de Santa Maria. En Medieval, Renaissance and Folklore Studies in Honor of John Esten Keller (pp. 53-66). Newark, Delaware: Juan de la Cuesta Press.

Snow, J. (2012). The poetry of Alfonso X. An annotated critical bibliography (1278-2010). Woodbridge: Tamesis.

Wulstan, D. (2000). The Compilation of the Cantigas of Alfonso el Sabio. En S. Parkinson. (Ed.), Cobras e son. Papers on the Text, Music and Manuscripts in the Cantigas de Santa Maria (pp. 154-185). Oxford: Oxford University.

\section{Notas}

1 Aunque la bibliografía sobre las Cantigas de Santa Maria [CSM] es muy amplia, los trabajos monográficos sobre el Códice de Florencia no son numerosos, por lo que resulta conveniente reunirlos en esta nota. Antonio García Solalinde (1918); Nella Aita (1921 y 1922); Jesús Montoya Martínez (1986); Joaquín Hernández Serna (1989); Ramón Fernández Pousa (1956); El Códice de Florencia (1991); Amparo García Cuadrado (1993); Connie L. Scarborough (2011); Rocío Sánchez Ameijeiras (2002); Laura Fernández Fernández (2005) y Elvira Fidalgo (2019). A estos estudios se suman un número considerable de trabajos en los que el Códice de Florencia se analiza en conexión con el resto de los manuscritos del cancionero alfonsí, muchos de ellos serán citados en el desarrollo del presente artículo. Para bibliografía general de la obra siempre resulta de máxima utilidad la consulta de Joseph Snow (2012) y la selección bibliográfica proporcionada por la "The Oxford Cantigas de Santa María database" vinculada al Center for the Study of the Cantigas de Santa Maria of Oxford University, dirigido por el profesor Stephen Parkinson, http://csm.mml.ox.ac.uk.

2 Agradezco a los directores del Dipartimento di Manoscritti e Rari de la BNCF, inicialmente a la Dra. Paola Pirolo, en la actualidad al Dr. David Speranzi, así como a todo el personal de la sala, su amable atención y ayuda para el desarrollo de mi trabajo. Una parte sustancial de la investigación realizada en 2004 puede leerse en Laura Fernández Fernández (2005, 2008-2009 y 2012-2013), y en este artículo sumo los últimos datos incorporados en febrero de 2020.

3 Los cuatro manuscritos de las CSM conservados son: To, Madrid, Biblioteca Nacional de España, Mss/10.069; T, El Escorial, Real Biblioteca del Monasterio de El Escorial [RBME], Ms. T-I-1; F, Firenze, BNCF Ms. BR 20; E, El Escorial, RBME Ms. b-I-2.

4 Para comprender la evolución y desarrollo del cancionero alfonsí, además de los clásicos estudios de Filgueira (1979), Mettmann (1986-1989) y Montoya (1987 y 1999), son fundamentales las lecturas de Elvira Fidalgo (1990, 1993, 2002), Martha E. Schaffer (1990-1991, 1999, 2000), Stephen Parkinson (1988, 2000b, 2007), y Stephen Parkinson y Deirdre Jackson (2006). En lo que respecta a aspectos musicales y su conexión con la articulación del cancionero véase Ferreira (1994, 2004, 2011 y 2015).

5 No obstante, como señala Elvira Fidalgo (2019, p. 386), las cantigas F14 (ff. 15v-16r) y la F86 (f. 109 v, falta el folio siguiente con la iluminación) no aparecen en $\mathrm{E}$.

6 Folios 32v, 36v, 56v,73v, 74v, 80v, 83v, 84v, 92v, 96v, 111v, 112v, 126v, y 127v. Tal y como podemos apreciar esta combinación siempre aparece en el vuelto de los folios.

7 Para explorar el contenido histórico de los poemas del cancionero sigue siendo de imprescindible lectura el libro de Evelyn Procter (1951) y Jonathan O’Callaghan (1998).

8 En To el rey aparece únicamente mencionado en la cantiga 16 (la 18 en T); en T aparece mencionado en la 142 y la 169 , pero también aparece representado en la 18, la 29 y en la 113. Además, en T, la visualización del monarca se centra en los prólogos y de manera contundente en su incorporación a las cantigas de loor, a excepción de las cantigas 60 y 180 (no sabemos cuál sería la iluminación de la 40 ya que estaría en uno de los folios que faltan en T). Si nos ceñimos a la numeración tradicional de Mettmann, en F y E el rey aparece mencionado en las cantigas 209, 215, 235, 243, 256, 257 , 279, 292, 295, 324, 328, 345, 348, 349, 354, 358, 361, 366, 367, 371, 376, 377, 382, 386, 398, y en la Petiçon, 401.

9 Sobre el complejo proceso de fuentes e influencias para la composición visual en las CSM la bibliografía es igualmente amplia, sin mencionar los numerosos trabajos centrados en cuestiones vinculadas con teoría de la imagen y aspectos iconográficos cuya cita resulta excesiva en este artículo. Para el estudio de la filiación estilística de las CSM siguen siendo lecturas fundamentales los trabajos de Gonzalo Menéndez Pidal (1951 y 1962) y Ana Domínguez Rodríguez (1976), y más recientemente Francisco Prado-Vilar (2002, 2005 y 2011) y Rocío Sánchez Ameijeiras (2002 y 2012-2013); para el análisis de la composición pictórica remito a las publicaciones de $\mathrm{M}^{a}$ Victoria Chico Picaza (1987, 2011 y 2012-2013).

10 Para el estudio de las diferentes fases de trabajo véase Parkinson y Jackson (2006) y Parkinson (2011); para el estudio de la evolución de los manuscritos véase Schaffer (1999 y 2000) y Fernández Fernández (2011 y 2012-2013). 
11 El protagonismo asumido por las cantigas cuya numeración finaliza en 5 ha sido relacionado con la dimensión simbólica del número 5 en el universo mariano por Martha Schaffer (1990-1991, p. 80) y Elvira Fidalgo (2002, p. 132). En el caso de E se abandona esta estructura copiándose una cantiga detrás de otra manteniéndose exclusivamente la estructura decenal establecida por los loores a través de la incorporación de las conocidas viñetas con la representación de intérpretes con sus instrumentos, lo que favoreció su rápida copia con respecto a $\mathrm{F}$.

12 Aunque aún no disponemos de un estudio paleográfico pormenorizado de conjunto, los trabajos realizados en este sentido consideran que un mismo copista copió $\mathrm{T}$ y $\mathrm{F}$ en lo que respecta al texto principal y copia buena parte de $\mathrm{E}$ (parece que también habría intervenido en To) (Fidalgo y Guiadanes, 2020). Para un estudio actualizado de la cronología de los manuscritos de las CSM véase Fernández Fernández (2011 y 2012-2013).

13 “195.- De los loores y milagros de nuestra Señora escrito también en verso. Esta obra es mencionada por Gonzalo Argote de Molina en su Historia (Nobleza de la Andalucía en el Índice de los libros que manejó), en la que trata de las familias que se establecieron en Andalucía mediante sus conquistas militares contra los moros, y que titula Cantares. Según nos comunicó por carta el señor Juan Lucas Cortés el día XIX de septiembre de MDCLXXIV desde Madrid el códice mismo que perteneció al rey, escrito en pergamino y pulcramente ilustrado y con preciosa caligrafía estuvo hace pocos años en poder de don Alfonso de Siliceo, gran bibliógrafo de todo género de ciencias, y actualmente se encuentra en su poder. En él se narran más de doscientos milagros, la mayor parte acaecidos en su época e igualmente se reseñan por el rey otros sucesos extraordinarios. En una página se escriben los versos que contienen lo antes indicado y en la siguiente se diseñan en miniatura los hechos con las figuras correspondientes. 196.- El mismo Juan Lucas Cortés sospecha que al códice le faltan algunas narraciones, o acaso la mayor parte del original. Ciertamente falta el milagro llamado de nuestra señora del Castillo de Chincoja que es citado por Argote en su Nobleza."

14 Agradezco a Antonio Carpallo su ayuda en la descripción de la encuadernación.

15 David Wulstan (2000, p. 162) ya había reconocido cinco de los cuadernos.

16 Tanto en el caso del Códice Rico como en el Códice de los músicos el sistema de ordenación utilizado es el de signaturas alfabéticas. Sobre aspectos codicológicos en los manuscritos de las CSM véase Fernández Fernández y Ruiz García, 2011 y Fernández Fernández 2012-2013.

17 La colación del manuscrito había sido en parte planteada en dos interesantes trabajos por Nella Aita (1922) y por Deirdre Jackson (2002). Presento en este trabajo la colación completa.

18 Véase tabla de equivalencias en Wulstan, 2000, p. 157. En el vuelto del último folio de ese cuaderno podría estar el texto equivalente a la cantiga F12a (E289, E396), de la que solo tenemos la iluminación en el f. 14r.

19 Aita (1922) considera que los cuatro folios restantes faltarían después del folio 58, pero de ser así se interrumpiría la secuencia texto-texto correlativa entre los folios 58 y 59.

20 En este caso resulta difícil observar el centro del cuaderno, que aparentemente estaría entre el 80 y el 81, pero es probable que haya sido rehecho a partir de los folios restantes y que el centro original estuviera entre el 79 bis y el 80.

21 Aita (1922) considera que los folios que faltan irían después del f. 90, sin embargo, esta propuesta no encajaría con la estructura del cuaderno ni con la numeración romana. No obstante, es cierto que el f. 90v muestra un elemento un tanto desconcertante, ya que se aprecian huellas de pigmento y de escritura de otro folio, como si hubiera estado pegado a él, pero estas trazas no se corresponden con lo que vemos en el folio siguiente, el 91r, lo que genera cierta confusión. Parece la huella de un folio con texto y con una inicial fitomorfa realizada con pigmento azul. Por otra parte, el folio 91 parece que ha sido raspado y reutilizado para el texto de una cantiga, cuando había sido inicialmente planteado como folio iluminado; se puede apreciar la huella de la orla y los diseños de arquitecturas en algunas de las viñetas.

22 Aita considera que serían dos, pero esa hipótesis no encajaría con la estructura del cuaderno.

23 No podemos considerar que este cuaderno fuera un ternión y no un cuaternión ya que entonces quedaría rota la Ley de Gregory con respecto al cuaderno anterior.

24 El folio 20r es correlativo al 19v, el 22r al 21v, el 30r al 29v, el 50r al 49v, el 58r al 57v, el 85r al 84v, el 94r al 93v, el $102 \mathrm{r}$ al $101 \mathrm{v}$. El resto de las conexiones no se pueden realizar por pérdidas de folios o porque el cuaderno empieza con una cantiga.

25 Esta numeración es visible en la mayor parte de los folios en el manuscrito, no así en el facsímil que presenta ciertas discrepancias.

26 Agradezco a Antoni Iglesias y Ricardo Pichel sus apreciaciones sobre esta numeración.

27 El folio en el que probablemente se encontraba la iluminación de la cantiga F7 (E256), la correspondiente a la historia de la sanación de doña Beatriz de Suabia, es uno de los folios perdidos, por lo tanto no sabemos si llegó a realizarse por los equipos alfonsíes pero todo hace pensar que sí, ya que las iluminaciones del primer y del segundo cuaderno original están completas. Sí lo hizo el pintor que continuó trabajando en el manuscrito años más tarde, pero en el espacio destinado a otra iluminación.

28 Sobre las intervenciones en F, además de los estudios ya mencionados, véase María Victoria Chico Picaza (1991) y Amparo García Cuadrado (1993). 